\title{
High Neutrophil/Lymphocyte Ratios in Symptomatic Pediatric COVID-19 Patients
}

\author{
Eren Yildiz ${ }^{1}$, Emrah Cigri $^{1}$, Zubeyde Dincer ${ }^{1}$, Mehmet Ali Narsat ${ }^{2}$ and Busra Calisir ${ }^{3}$ \\ ${ }^{1}$ Department of Pediatrics, Kastamonu Training and Research Hospital, Kastamonu, Turkey \\ ${ }^{2}$ Department of Pediatric Surgery, Kastamonu Training and Research Hospital, Kastamonu, Turkey \\ ${ }^{3}$ Department of Microbiology, Kastamonu Training and Research Hospital, Kastamonu, Turkey
}

\begin{abstract}
Objective: To investigate the symptoms and laboratory results of children hospitalised with the diagnosis of COVID-19, aiming to reveal the characteristics of symptomatic cases.

Study Design: A descriptive cross-sectional study.

Place and Duration of Study: Department of Pediatrics, Kastamonu Training and Research Hospital, Kastamonu, Turkey from March to December 2020.

Methodology: Seventy-nine children, hospitalised with the diagnosis of COVID-19, were included in the study and were divided into two groups as symptomatic and asymptomatic. The demographic data, laboratory results and clinics of the patients of the two groups were compared.

Results: The mean age of participants was $10.43 \pm 5.91(0-17)$ years, and $57 \%(n=45)$ of them were girls. Five patients in the symptomatic group had comorbidities ( 2 allergic asthma, cerebral palsy, type-1 diabetes mellitus and anorexia nervosa). The most common symptom was fever $(36.7 \%, n=29)$. It was noteworthy that everyone with an NLR $>3.13$ (high-NLR) was symptomatic. Significantly more patients in the high-NLR group were symptomatic compared with the low-NLR group $(p=0.005)$. On the other hand, symptomatic children had significantly higher levels of C-reactive protein (2.8 (IQR: 1.2-10.0) mg/L vs. 1.4 (IQR: $0.4-2.0) \mathrm{mg} / \mathrm{L}, \mathrm{p}=0.011$ ); and procalcitonin (0.05 (IQR: $0.02-0.10) \mathrm{ng} / \mathrm{mL}$ vs. 0.01 (IQR: $0.00-0.03) \mathrm{ng} / \mathrm{mL}, \mathrm{p}<0.001$ ) than those without symptoms. One of the children with cerebral palsy died from pneumonia during the study.

Conclusion: C-reactive protein, procalcitonin and NLR levels were found to be significantly higher in symptomatic children. NLR can be suggested as a potential marker associated with disease severity in COVID-19 patients, which needs to be supported by other studies.
\end{abstract}

Key Words: COVID-19, Children, Neutrophil / lymphocyte ratio, C-reactive protein, Procalcitonin.

How to cite this article: Yildiz E, Cigri E, Dincer Z, Narsat MA, Calisir B. High Neutrophil/Lymphocyte Ratios in Symptomatic Pediatric COVID-19 Patients. J Coll Physicians Surg Pak 2021; 31(JCPSPCR):CR93-CR98.

\section{INTRODUCTION}

After the World Health Organization (WHO) declared COVID-19 as a pandemic on March 11,2020, ${ }^{1}$ it has quickly become one of the world's most prominent public health problems. On December 19, 2020, 74,299,042 cases and 1,669,982 deaths worldwide were confirmed by the $\mathrm{WHO}^{2}$, while 2,004,285 patients and 17,851 deaths were approved by the Ministry of Health of the Republic of Turkey. ${ }^{3}$

COVID-19 has a high spread rate. Besides, it has caused deaths and disabilities and significant economic losses.

Correspondence to: Dr. Eren Yildiz, Department of Pediatrics, Kastamonu Training and Research Hospital, Kastamonu, Turkey

E-mail: eren70@gmail.com

Received: January 03, 2021; Revised: March 21, 2021;

Accepted: April 28, 2021

DOI: https://doi.org/10.29271/jcpsp.2021.JCPSPCR.CR93
In addition, the shortage of effective treatment or vaccination is an issue that has not been fully resolved. As the disease is relatively new, it is essential to enrich information about it. For example, it is an informative question to ask why the course of COVID-19 affects different groups, such as children, with varying severity. The overall assessment is that the immune systems of children and adults differ in both their composition and functional responsiveness. ${ }^{4}$

While their role in transmission is still unclear, clinical findings in children, in whom exposure to the virus has been reported mostly from household contact, indicate that infected children tend to be asymptomatic compared to adult cases. ${ }^{5}$ Although the prognosis has been much better for children compared to adults until now, with the progress of the pandemic, the course of the disease in children may change in the future. ${ }^{6}$ Therefore, supervising the course of COVID-19 in children is still important. Knowing more about the disease will guide us in managing this disease and tackle its social and economic impacts. 
Table I: Characteristics of children with COVID-19.

\begin{tabular}{|c|c|c|c|}
\hline & & $\mathbf{N}$ & $\%$ \\
\hline \multirow{9}{*}{ Application month } & April & 7 & 8.9 \\
\hline & May & 11 & 13.9 \\
\hline & June & 19 & 24.1 \\
\hline & July & 25 & 31.6 \\
\hline & August & 6 & 7.6 \\
\hline & September & 2 & 2.5 \\
\hline & October & 2 & 2.5 \\
\hline & November & 4 & 5.1 \\
\hline & December & 3 & 3.8 \\
\hline \multirow{2}{*}{ Residence } & Rural & 13 & 16.5 \\
\hline & Urban & 66 & 83.5 \\
\hline Comorbidity & & 5 & 6.3 \\
\hline Fever & & 29 & 36.7 \\
\hline Cough & & 27 & 34.2 \\
\hline Dyspnea & & 4 & 5.1 \\
\hline Tachypnea & & 1 & 1.3 \\
\hline Diarrhea & & 11 & 13.9 \\
\hline Anosmia & & 4 & 5.1 \\
\hline Headache & & 6 & 7.6 \\
\hline Sore throat & & 12 & 15.2 \\
\hline Myalgia & & 6 & 7.6 \\
\hline
\end{tabular}

Comorbid disease and changes in laboratory values such as neutrophils, D-dimers, lymphocytes, interleukin-6 and C-reactive protein may be associated with poor prognosis. Neutrophillymphocyte ratio (NLR) and platelet-lymphocyte ratio (PLR), which can easily be reached with routine laboratory tests, can provide important information about the course of the disease.,

The aim of this study was to investigate the clinical conditions (being symptomatic or asymptomatic) and laboratory results of children admitted to the hospital with COVID-19, and to find out whether there was a relationship between them.

\section{METHODOLOGY}

This descriptive cross-sectional study was conducted among children hospitalised with the diagnosis of COVID-19 at the Department of Pediatrics, Kastamonu Training and Research Hospital, Kastamonu, Turkey between March and December 2020. Patient data were obtained from the hospital automation system.

Ethical approval No. 2020-KAEK-143-12.01, dated December $14,2020)$ was received from the Faculty of Medicine Clinical Research Ethics Committee.

The Hospital is a hospital with 72 polyclinics, serving more than 1 million patients annually. The Department of Pediatrics has a capacity of 60 beds, welcoming approximately 100,000 patients for outpatient treatment and 7,000 inpatients every year.

During the study period, 80,699 children applied to the Hospital. Of these, 4091 patients who had symptoms suggestive of COVID-19 or a history of contact with someone having the disease, were identified as "suspected COVID-19 cases". However, 949 of these patients were diagnosed as COVID-19, 79 of them were hospitalised and included in the study. The patients were divided into two groups as symptomatic and asymptomatic. The demographic data, laboratories and clinics of the patients of the two groups were compared.

Of the 79 hospitalised patients, 29 were asymptomatic and 50 were symptomatic. All patients diagnosed with COVID-19 were hospitalised and treated with the recommendations of the National Ministry of Health; and according to these recommendations $\mathrm{CBC}$, CRP, procalcitonin, biochemistry and venous blood gas tests were evaluated. ${ }^{9}$ Furthermore, the diagnosis of COVID-19 was confirmed by polymerase chain reaction (PCR).

The PCR test kits for COVID-19 were provided by the Public Health Directorate General of Turkey. The method was studied in line with the recommendations of the Bio-Speedy Covid-19 RT-qPCR Detection Kit (Bio-eksen Ar-Ge, Istanbul, Turkey).

The severity of the pediatric COVID-19 cases were categorised as follows: (a) Asymptomatic patients with positive PCR but no other findings; (b) mild disease included patients with acute upper respiratory tract infection, but without pneumonia; (c) moderate disease includes cases with pneumonia and respiratory tract infection symptoms; (d) severe disease includes cases with central cyanosis, progressive respiratory illness, and shortness of breath (e) critical disease, including those who presented with critically ill acute respiratory distress syndrome or respiratory failure, shock, and organ dysfunction. ${ }^{10}$ Those with mild, moderate, severe and very severe disease were included in the symptomatic group.

The primary outcome variable of the study was the neutrophil lymphocyte ratio (NLR). Secondary outcome variables were gender, place of residence, the presence of fever, cough, headache, dyspnea, tachypnea, diarrhea, anosmia, sore throat, myalgia, contact with a known COVID-19 patient, and comorbidity. Additionally, data was collected on the following numerical secondary outcome variables: age (years), glucose ( $\mathrm{mg} / \mathrm{dL})$, total bilirubin (mg/dL), D-dimer $(\mathrm{ng} / \mathrm{mL})$, lactate $(\mathrm{mmol} / \mathrm{L}), \mathrm{C}$-reactive protein (CRP) (mg/L), white blood cell (WBC) count $\left(10^{3} / \mu \mathrm{L}\right)$, procalcitonin $(\mathrm{ng} / \mathrm{mL})$, neutrophil count (NEU) $\left(10^{3} / \mu \mathrm{L}\right)$, lymphocyte count (LYM) $\left(10^{3} / \mu \mathrm{L}\right)$, platelet (PLT) count $\left(10^{3} / \mu \mathrm{L}\right)$, creatinine $(\mathrm{mg} / \mathrm{dL})$, peripheral venous oxygen saturation $\left(\mathrm{PO}_{2}\right)$ $(\%)$, power of hydrogen $(\mathrm{pH})$, international normalised ratio (INR), aspartate transaminase (AST) (U/L), alanine transaminase $(\mathrm{ALT})(\mathrm{U} / \mathrm{L})$, triglyceride $(\mathrm{TG})(\mathrm{mmol} / \mathrm{L})$, ferritin $(\mathrm{ng} / \mathrm{mL})$, lactate dehydrogenase (LDH) (U/L), troponin $(\mathrm{ng} / \mathrm{mL})$, duration of PCR positivity (day), and erythrocyte sedimentation rate (ESR).

Data were analysed using the Statistical Package for Social Sciences 25.0 software (SPSS Inc., Chicago, IL, USA). Results were presented as means \pm standard deviations or median (IQR: 25th percentile-75th percentile) according to normal distribution compliance for numerical variables, as well as frequencies and percentagesforcategorical data. The compatibility of numerical variables to normal distribution was evaluated by the Shapiro-Wilk test. 
Table II: Comparison of categorical variables in terms of the presence of symptoms.

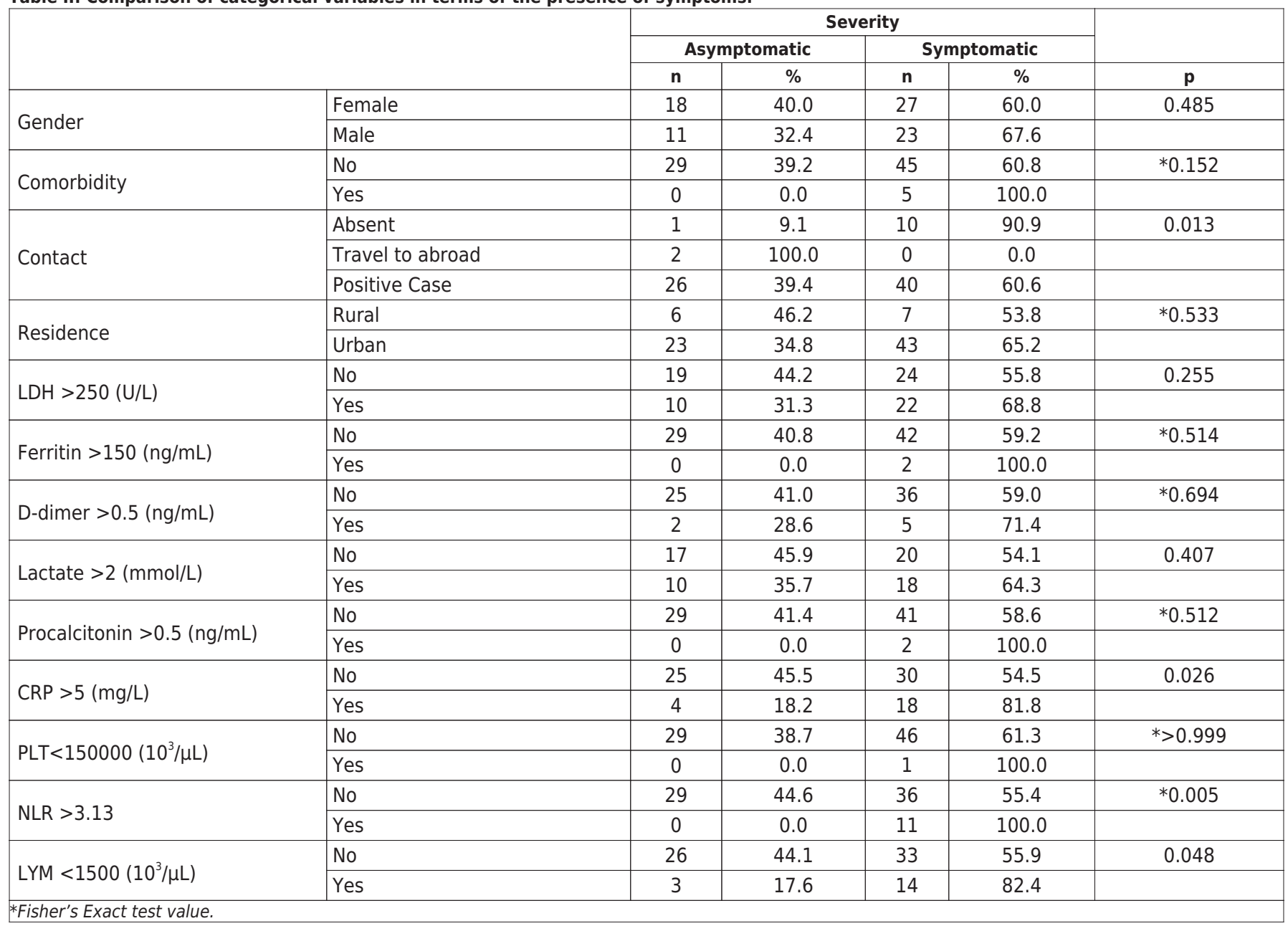

Comparisons were evaluated with the independent samples t-test or Mann-Whitney U-test for numerical variables, while Chi-square or Fisher's Exact test was used for categorical variables. The significance threshold was taken as $p<0.05$.

\section{RESULTS}

The mean age of the participants was $10.43 \pm 5.91(0-17)$ years, and $57 \%(n=45)$ of them were females. Most of the applications were in July, followed by June and May. The most common symptom was fever $(36.7 \%)$, followed by cough (34.2\%, Table I).

In our study, there were 29 patients in the asymptomatic group, and 50 patients in the symptomatic group consisting of 43 mild, six moderate and one critical patients. Asymptomatic and mild cases represented $91.1 \%$ of all cases. There was no statistically significant difference in gender between the asymptomatic group and the symptomatic group. Five patients in the symptomatic group had comorbidities; allergic asthma $(n=2)$ and one case cerebral palsy each of, type-1 diabetes mellitus and anorexia nervosa. All patients with comorbidity were symptomatic. However, no statistically significant difference was found between having symptoms concerning co-morbidity. The patients were grouped as rural and urban as their place of residence, and no statistically significant difference was found between the two groups in terms of symptoms.Asymptomatic and symptomatic groups 250 (U/L) for $\mathrm{LDH}, 150(\mathrm{ng} / \mathrm{mL})$ for ferritin, 0.5 ( $\mathrm{ng} / \mathrm{mL})$ for D-dimer, $2(\mathrm{mmol} / \mathrm{L})$ for lactate, and $0.5(\mathrm{ng} / \mathrm{mL})$ for procalcitonin was compared on the basis of being above the cut-off values. There was no statistically significant difference between these two groups. It was noteworthy that everyone with an NLR $>3.13$ (high-NLR) was symptomatic. Significantly more patients in the high-NLR group were symptomatic compared with the low-NLR (Table II). Symptomatic children had significantly higher NLR levels, CRP, procalcitonin, and a lower percentage of LYM than those without symptoms (Table III).

Table III: Comparison of numerical variables regarding the presence of symptoms.

\begin{tabular}{|c|c|c|c|c|c|}
\hline & \multicolumn{2}{|c|}{ Asymptomatic } & \multicolumn{2}{|c|}{ Symptomatic } & \multirow[b]{2}{*}{$\mathbf{p}$} \\
\hline & Median (IQR) & $\mathbf{n}$ & Median (IQR) & $\mathbf{n}$ & \\
\hline Age (years) & $13(10-14)$ & 29 & $12(2-16)$ & 50 & 0.728 \\
\hline
\end{tabular}




\begin{tabular}{|c|c|c|c|c|c|}
\hline WBC $\left(10^{3} / \mu \mathrm{L}\right)$ & $6130(4840-7320)$ & 29 & $6970(5000-10100)$ & 47 & 0.225 \\
\hline LYM\% & $46.0(34.0-51.0)$ & 29 & $34.0(22.0-46.0)$ & 47 & 0.024 \\
\hline $\operatorname{NEU}\left(10^{3} / \mu \mathrm{L}\right)$ & $2510(1860-3970)$ & 29 & $2920(2090-5080)$ & 47 & 0.108 \\
\hline NLR & $0.95(0.71-1.70)$ & 29 & $1.60(0.93-3.18)$ & 47 & 0.032 \\
\hline PLR & $105(88-126)$ & 29 & $125(83-168)$ & 47 & 0.252 \\
\hline $\mathrm{CRP}(\mathrm{mg} / \mathrm{L})$ & $1.4(0.4-2.0)$ & 29 & $2.8(1.2-10.0)$ & 48 & 0.011 \\
\hline Procalcitonin (ng/L) & $0.01(0.00-0.03)$ & 29 & $0.05(0.02-0.10)$ & 44 & $<0.001$ \\
\hline $\mathrm{pH}$ & $7.35(7.32-7.36)$ & 27 & $7.38(7.34-7.41)$ & 38 & 0.005 \\
\hline pO2 & $30.0(23.0-36.0)$ & 27 & $35.5(23.0-48.0)$ & 38 & 0.269 \\
\hline Lactate (mmol/L) & $1.70(1.40-2.20)$ & 27 & $1.90(1.40-2.90)$ & 38 & 0.144 \\
\hline Glucose (mg/dL) & $99(90-106)$ & 29 & $101(90-112)$ & 48 & 0.430 \\
\hline Total bilirubin (mg/dL) & $0.27(0.22-0.38)$ & 29 & $0.35(0.22-0.50)$ & 48 & 0.155 \\
\hline D-dimer $(\mathrm{ng} / \mathrm{mL})$ & $0.34(0.24-0.45)$ & 27 & $0.45(0.28-0.57)$ & 41 & 0.156 \\
\hline AST (U/L) & $23(18-28)$ & 29 & $23(18-38)$ & 48 & 0.203 \\
\hline $\mathrm{ALT}(\mathrm{U} / \mathrm{L})$ & $13(10-19)$ & 29 & $17(12-22)$ & 48 & 0.340 \\
\hline Triglyceride (mmol/L) & $80(64-156)$ & 29 & $94(57-137)$ & 44 & 0.731 \\
\hline Ferritin $(\mathrm{ng} / \mathrm{mL})$ & $20.00(18.00-31.00)$ & 29 & $29.00(15.00-56.00)$ & 45 & 0.118 \\
\hline LDH (U/L) & $221(188-277)$ & 29 & $248(197-284)$ & 46 & 0.349 \\
\hline ESR $(\mathrm{mm} / \mathrm{h})$ & $11(8-18)$ & 23 & $11(8-15)$ & 32 & 0.325 \\
\hline Troponin $(\mathrm{ng} / \mathrm{mL})$ & $2.00(2.00-2.00)$ & 29 & $2.00(2.00-2.50)$ & 44 & 0.307 \\
\hline \multirow[t]{2}{*}{ Duration of PCR positivity (day) } & $5(5-6)$ & 28 & $5(5-7)$ & 31 & 0.180 \\
\hline & Mean \pm SD & $\mathrm{n}$ & Mean \pm SD & $\mathrm{N}$ & $*_{p}$ \\
\hline $\operatorname{LYM}\left(10^{3} / \mu \mathrm{L}\right)$ & $2726.2 \pm 974.4$ & 29 & $2553 \pm 1669.6$ & 47 & 0.570 \\
\hline NEU\% & $44.8 \pm 13.1$ & 29 & $52.3 \pm 19.0$ & 47 & 0.066 \\
\hline $\operatorname{PLT}\left(10^{3} / \mu \mathrm{L}\right)$ & $261.59 \pm 51.76$ & 29 & $255.11 \pm 55.51$ & 47 & 0.614 \\
\hline Creatinine (mg/dL) & $0.51 \pm 0.14$ & 29 & $0.87 \pm 2.68$ & 48 & 0.477 \\
\hline INR & $0.94 \pm 0.05$ & 27 & $0.94 \pm 0.18$ & 37 & 0.925 \\
\hline
\end{tabular}

One of the children died during the study from pneumonia. The computed tomography image showed increased ground glass density with a round configuration, covering the entire left lung and the periphery of the right lung.

\section{DISCUSSION}

Studies have shown that compared to adults, COVID-19 has a milder clinical course with faster recovery and better prognosis in children. ${ }^{7,8}$ However, studies in the pediatric population are more limited than those in the adult population. ${ }^{4}$

In general, lymphopenia reflects the weakness of cellular immunity, while neutrophilia is a parameter that indicates the response to systemic inflammation. The ratio of these two values to each other can be interpreted as showing the adequacy of the cellular immune response in response to the magnitude of systemic inflammation. As a matter of fact, studies show that these data can be used to predict the prognosis of various conditions, such as cardiovascular disease, cancers, and inflammatory diseases. ${ }^{11-13}$

In a retrospective study, data from 153 patients with acute pulmonary embolism (PE) were evaluated by multiple logistic regression; and it was reported that NLR could be used as a risk factor predicting 30-day mortality in PE. ${ }^{14}$
Additionally, it has been reported that NLR can be a useful marker of systemic inflammation for screening patients infected with COVID-19 and can be used as a marker that can predict poor prognosis even during hospitalisation. ${ }^{15}$ Furthermore, it has been stated that NLR can predict prognosis in patients over 50 years. ${ }^{16}$

On the other hand, there is insufficient data on the relationship between COVID-19 and NLR in children. This study showed that NLR is increased in children with COVID-19, and all symptomatic children have high NLR (>3.13). This finding should stimulate further research.

Besides, a meta-analysis suggested that doctors should closely monitor lymphocyte count, WBC count, platelet count, IL-6, and serum ferritin as potential indicators of progression to critical disease in COVID-19 patients. ${ }^{17}$ Additionally, high CRP, procalcitonin, and low lymphocyte levels in this study suggested that another underlying infection may have been contributed to the symptoms. Therefore, we recommend screening of the symptomatic pediatric COVID-19 patients for the presence of other underlying infections.

Although less common than adults, fever and cough are the two most common symptoms in pediatric patients with 
COVID-19. ${ }^{18}$ In this population, fever is detected in approximately $40 \%$ to $60 \%$ of COVID-19 cases and has been reported as a dominant symptom related to cough and common symptoms of rhinopharyngitis, such as rhinorrhea and sore throat. $6,19-22$

A study conducted in Turkey indicated that fever was detected in $40.5 \%$ of pediatric patients at any time during the illness. ${ }^{19}$ In the same research, cough was the second most common symptom (35.9\% of cases), followed by fatigue or myalgia (16.4\%), sore throat (16.8\%), diarrhea $(7.7 \%)$, headache $(9.1 \%)$, vomiting $(4.1 \%)$, respiratory problems $(4.1 \%)$, anosmia (5\%), and conjunctivitis $(1.4 \%){ }^{19}$ Another study performed in Turkey found that the incidence of symptoms at the time of application was 58\% for fever, $52 \%$ for cough, and $19 \%$ for fatigue or myalgia. ${ }^{23}$

In this study, while the rates of fever and cough were lower than in previous studies, the frequency of diarrhea was higher. At the beginning of the outbreak, all patients with a positive test or contact history were investigated in the hospital. Later, the management protocol was modified in the way that only symptomatic cases were hospitalized. This policy change may have caused a difference in reported rates between the studies.

Mortality among children with COVID-19 is rare. When the number of 9,799 deaths from COVID-19 were reported in Turkey, only 17 of them were children at or under 15 years. ${ }^{24}$ As a matter of fact, the only case who died from pneumonia in our study was a 17-year-old patient with cerebral palsy. Respiratory dysfunction is more common in patients with cerebral palsy, and it causes morbidity and mortality. ${ }^{25}$

Risk factors for mortality and morbidity in children with COVID-19 are the same for adults, including comorbidities, such as diabetes, chronic pulmonary disease, and cardiac pathology. ${ }^{26}$ In a study examining 48 children admitted to North American pediatric intensive care units due to COVID-19, co-morbidity was present in $83 \%$ of the patients. ${ }^{27}$ In the study, all children with comorbidity showed symptoms, but there was no statistically significant difference between those who had symptoms and those who did not. The low number of people with comorbidity may have affected this situation. However, this difference may become significant in studies conducted with more children having comorbidities.

The general limitations of retrospective studies also apply to this research. Additionally, the lack of cultural results of the participants may be considered as another limitation. This has led to the inability to exclude the presence of another underlying infection. Since the patient group to be hospitalised and treated was determined according to the recommendations of the National Ministry of Health during the pandemic, asymptomatic and mild patients in the later period of the pandemic were monitored on an outpatient basis and were not included in this study. This is a limitation of our study.

\section{CONCLUSION}

The presence of secondary infection should be investigated in symptomatic children, who are positive for COVID-19. Thus, the NLR may be suggested as a potential marker associated with disease severity in COVID-19 patients. However, this speculation needs to be supported by other studies. Furthermore, patients with cerebral palsy should be monitored more closely, if they have COVID-19.

\section{ETHICAL APPROVAL:}

Ethics Committee approval was received from the Ethics Committee of Kastamonu University Faculty of Medicine (No. 2020-KAEK-143-12.01, dated December 14, 2020).

\section{PATIENTS' CONSENT:}

Because this study was retrospective, the condition of patients' consent was waived.

\section{CONFLICT OF INTEREST:}

The authors declared no conflict of interest.

\section{AUTHORS' CONTRIBUTION:}

EY: Carried out the conception and design of the research, drafted the manuscript and performed the statistical analysis.

EÇ: Participated in the acquisition of data.

ZD, MAN, BC: Carried out the analysis and interpretation of data.

All authors read and approved the final manuscript.

\section{REFERENCES}

1. Cucinotta D, Vanelli M. WHO declares COVID-19 a Pandemic. Acta Biomed 2020; 91(1):157-60. doi: 10.23750/ abm.v91i1.9397.

2. WHO. WHO Coronavirus Disease (COVID-19) Dashboard 2020. http://covid19.who.int/ (accessed December 20, 2020).

3. Republic of Turkey Ministry of Health. COVID-19 Information page 2020. http://covid19.saglik.gov.tr/ (accessed December 20, 2020).

4. Brodin P. Why is COVID-19 so mild in children? Acta Paediatr 2020; 109(6):1082-3. doi: 10.1111/apa.15271.

5. Giacomet V, Stracuzzi M, Paradiso L, Di Cosimo ME, Rubinacci $V$, Zuccotti G. Defining the clinical phenotype of COVID-19 in children. Pediatr Allergy Immunol 2020; 31 Suppl 26(Suppl 26):82-4. doi: 10.1111/pai.13355.

6. Ciuca IM. COVID-19 in children: An ample review. Risk Manag Healthc Policy 2020; 13:661-9. doi: 10.2147/RMHP. S257180.

7. Chen ZM, Fu JF, Shu Q, Chen YH, Hua CZ, Li FB et al. Diagnosis and treatment recommendations for pediatric respiratory infection caused by the 2019 novel coronavirus. World J Pediatr 2020; 16(3):240-6. doi: 10.1007/s12519- 020-00345-5 
8. Li Y, Guo F, Cao Y, Li L, Guo Y. Insight into COVID-2019 for pediatricians. Pediatr Pulmonol 2020; 55(5):E1-4. doi: 10.1002/ppul.24734.

9. http://www.tahud.org.tr/file/58f0a672-b2e0-482e-bf7c-617 49426bac7/COVID-19_11Mart2020.pdf (Accessed on 21/3/ 2021).

10. Dong $Y$, Mo X, Hu Y, Qi X, Jiang F, Jiang, Z, et al. Epidemiological characteristics of 2143 pediatric patients with 2019 coronavirus disease in China. Pediatrics 2020; 145(6): e20200702. DOI: 10.1542/peds.2020-07023.

11. Angkananard T, Anothaisintawee T, McEvoy M, Attia J, Thakkinstian A. Neutrophil lymphocyte ratio and cardiovascular disease risk: A systematic review and meta-analysis. Biomed Res Int 2018; 2018:2703518. doi: 10.1155/2018/ 2703518.

12. Hu Y, Cheng $Y, X u X$, Yang B, Mei F, Zhou Q, et al. Pretreatment neutrophil-to-lymphocyte ratio predicts prognosis in patients with diabetic macular edema treated with ranibizumab. BMC Ophthalmol 2019; 19(1):194. doi: 10.1186/s12886-019-1200-4.

13. Kuzucu I, Güler I, Kum RO, Baklacı D, Özcan M. Increased neutrophil lymphocyte ratio and platelet lymphocyte ratio in malignant parotid tumors. Braz J Otorhinolaryngol 2020; 86(1):105-10. doi: 10.1016/ j.bjorl.2019.02.009.

14. Jia D, Liu F, Zhang Q, Zeng GQ, Li XL, Hou G. Rapid on-site evaluation of routine biochemical parameters to predict right ventricular dysfunction in and the prognosis of patients with acute pulmonary embolism upon admission to the emergency room. J Clin Lab Anal 2018; 32(4):e22362. doi: 10.1002/jcla.22362.

15. Pimentel GD, Vega MCM Dela, Laviano A. High neutrophil to lymphocyte ratio as a prognostic marker in COVID-19 patients. Clin Nutr ESPEN 2020; 40:101-2. doi: 10.1016/ j.clnesp.2020.08.004

16. Liu J, Liu Y, Xiang P, Pu L, Xiong H, Li C, et al. Neutrophil-to-lymphocyte ratio predicts critical illness patients with 2019 coronavirus disease in the early stage. J Transl Med 2020; 18(1):206. doi: 10.1186/s12967-020-02374-0.

17. Henry BM, de Oliveira MHS, Benoit S, Plebani M, Lippi G. Hematologic, biochemical and immune biomarker abnormalities associated with severe illness and mortality in coronavirus disease 2019 (COVID-19): A meta-analysis. Clin Chem Lab Med 2020; 58(7):1021-8. doi: 10.1515/ cclm-2020-0369.

18. Li B, Zhang S, Zhang R, Chen X, Wang Y, Zhu C. Epidemiological and clinical characteristics of COVID-19 in children: A systematic review and meta-analysis. Front Pediatr 2020; 8:591132 doi: 10.3389/fped.2020.591132.

19. Cura Yayla BC, Özsürekçi Y, Aykaç K, Derin Oygar P, Laçinel Gürlevik S, illbay S, et al. Characteristics and management of children with COVID-19 in Turkey. Balkan Med J 2020; 37(6):341. doi: 10.4274/balkanmedj.galenos.2020.2020. 7.52 .

20. Korean society of infectious diseases; Korean society of pediatric infectious diseases; Korean society of epidemiology; Korean society for antimicrobial therapy; Korean society for healthcare-associated infection control and prevention; Korea centers for prevention. Report on the epidemiological features of Coronavirus Disease 2019 (COVID-19) outbreak in the republic of Korea from January 19 to March 2, 2020. J Korean Med Sci 2020; 35:e112.

21. Xia W, Shao J, Guo Y, Peng X, Li Z, Hu D. Clinical and CT features in pediatric patients with COVID-19 infection: Different points from adults. Pediatr Pulmonol 2020; 55(5): 1169-74. doi: 10.1002/ppul.24718.

22. Lu X, Zhang L, Du H, Zhang J, Li YY, Qu J, et al. SARS-CoV-2 infection in children. N Engl J Med 2020; 382:1663-5. DOI: 10.1056/NEJMc2005073.

23. Korkmaz MF, Türe E, Dorum BA, Kılıç ZB. The epidemiological and clinical characteristics of 81 children with COVID-19 in a pandemic hospital in Turkey: An observational cohort study. J Korean Med Sci 2020; 35(25):e236. doi: 10.3346/jkms.2020.35.e236.

24. Republic of Turkey Ministry of Health. COVID-19 Weekly Situation Report 19/10/2020 - 25/10/2020 Turkey 2020:6. http://covid19.saglik.gov.tr/Eklenti/39230/0/covid-19-weekly -situation-report43pdf.pdf?_tag1=D3D202441F1F5165A33 D16981E6544EF7FC0A32F (accessed December 20, 2020).

25. Brandenburg JE, Fogarty MJ, Sieck GC. Why individuals with cerebral palsy are at higher risk for respiratory complications from COVID-19. J Pediatr Rehabil Med 2020; 13(3):317-27. doi: 10.3233/PRM-200746.

26. Guan WJ, Ni ZY, Hu Y, Liang WH, Ou CQ, He JX, et al. Clinical characteristics of coronavirus disease 2019 in China. N Engl J Med 2020; 382:1708-20. DOI: 10.1056/NEJM oa2002032.

27. Shekerdemian LS, Mahmood NR, Wolfe KK, Riggs BJ, Ross CE, McKiernan CA, et al. Characteristics and outcomes of children with coronavirus disease 2019 (COVID-19) infection admitted to US and Canadian pediatric intensive care units. JAMA Pediatr 2020; 174(9):868-74. doi: 10.1001/ jamapediatrics.2020.1948. 